\title{
SABERES E APRENDIZAGENS: ENTRE OS NÚMEROS E AS PESSOAS
}

KNOWLEDGE AND LEARNING: BETWEEN NUMBERS AND INDIVIDUALS

SABERES Y APRENDIZAJES: ENTRE LOS NÚMEROS Y LAS PERSONAS

José Augusto Brito Pacheco ${ }^{1}$

${ }^{1}$ Doutor em Ciências da Educação pela UMINHO, Braga, Portugal.

Resumo: Não se esgotam as ideias sobre a educação e mais ainda sobre as suas finalidades, sempre num pêndulo oscilante entre o social, de âmbito cultural, político e ideológico, e o pessoal, na esfera do sujeito e da multiplicidade de subjetividades que o tornam em pessoa. Desde os escritos filosóficos até aos sociológicos e pedagógicos, a educação e a formação têm sempre em vista saberes e aprendizagens, geralmente discutidos em propostas curriculares - sim, porque o currículo é conhecimento - diferentemente perspetivadas. São analisadas neste texto as racionalidades de Estado, Sujeito e Mercado como abordagens oscilando entre os números e as pessoas.

Palavras-chave: Estado; Sujeito; Mercado; Currículo.

Abstract: There are endless ideas about education, and even more about its purposes, with the pendulum constantly swinging between the cultural, political, ideological and personal contexts, in the shere of the subject and the multiplicity of subjectivities that make it a person. From philosophical, through to sociological and pedagogical writings, education and training always have in sight knowledge and learning in mind, usually discussed in curricular proposals - yes, since curriculum is knowledge - from different perspectives. This paper analyzes the rationalities of State, Subject and Market as approaches that swing between numbers and individuals.

Key-words: State; Subject; Market; Curriculum.

Resumen: No se agotan las ideas sobre la educación y más aún sobre sus finalidades, siempre en un péndulo oscilante entre lo social, de ámbito cultural, político e ideológico, y lo personal, en la esfera del sujeto y de la multiplicidad de subjetividades que lo hacen en persona. Desde los escritos filosóficos hasta los sociológicos y pedagógicos, la educación y la formación siempre tienen en cuenta los saberes y aprendizajes, generalmente discutidos en propuestas curriculares - sí, porque el currículo es conocimiento - a diferencia de las perspectivas. Se analizan en este texto las racionalidades de Estado, Sujeto y Mercado como abordajes oscilando entre los números y las personas.

Palabras clave: Estado; Sujeto; Mercado; Currículo. 


\section{INTRODUÇÃO}

Há muitos modos de olhar, de forma realista e crítica, para a escola, ou seja, para o espaço público de educação e formação, consagrado pelo princípio iluminista do esclarecimento, alicerçado na ideia de bildung, ou de cultura e processo de formação de que o indivíduo deve participar. Apesar das diversas perspetivas sobre a escola, sobretudo na fundamentação de um processo de escolarização que se tornou obrigatório e consagrado como direito universal, há lógicas que necessitam de ser repensadas a partir de uma atitude investigativa, ou seja, de questionamento contínuo, uma vez que não há respostas definitivas sobre as suas dimensões. Assim, analisam-se neste texto as principais racionalidades em educação e formação - Estado, Sujeito e Mercado - que surgem quando educadores e professores procuram responder a esta questão fundacional dos Estudos Curriculares: Que conhecimento é mais valioso? (PINAR, 2007; PACHECO, 2005).

\section{ESTADO}

Sendo "um lugar de um poder universalmente reconhecido" (BOURDIEU, 2014, p. 132) e de interesses legitimados em termos sociais, que conferem a diversidade de princípios para a sua fundamentação, o Estado é discutido muito teoricamente, mas se aceita quando se interligam público e privado, mesmo que haja o forte reconhecimento da sociedade civil. Recorrendo à história crítica do holocausto, Snyder (2016, p. 477) justifica o Estado pelo "reconhecimento, o apoio e a proteção de direitos, o que significa criar as condições sob as quais tais direitos podem ser reconhecidos, apoiados e protegidos".

O Estado subsiste para criar uma "sensação de durabilidade" (SNYDER, 2106, p. 477), pelo que a sua dissolução, como aconteceu em muitos países europeus destruídos pela II Guerra Mundial, pode ser o caminho direto para a barbárie. E esclarece, ainda, o historiador: "Quando não temos uma sensação de passado ou de futuro, o presente parece uma plataforma trémula, uma base incerta para a ação. Defender Estados e direitos é impossível de empreender se ninguém aprender com o passado ou acreditar no futuro. A consciência da história permite o reconhecimento de armadilhas ideológicas e cria o ceticismo sobre a busca de ação imediata porque tudo mudou de repente" (SNYDER, 2016, p. 477).

A finalidade social da educação, uma matriz de formação edificada nos pilares do Estado e da Nação e que inclui saberes, capacidades, atitudes, valores e comportamentos, numa dimensão universal, orientados para uma cidadania global, mais ainda a partir do momento em que a escola é um aparelho ideológico do Estado, na ideia althusseriana, sendo de frequência obrigatória, sucessivamente alargada no espaço de dois séculos, estando em muitos dos sistemas educativos em 12 anos de escolaridade obrigatória, ao nível do que deve ser uma Educação Básica. Tal finalidade pode ser resumida pela importância que Adorno (1971/2011) atribui à educação: simplesmente para que a barbárie não volte a acontecer, ou seja, a intolerância humana, tão presente no holocausto, jamais coloque em causa a condição humana 
(ARENDT, 2006).

Numa dimensão cultural, o Estado tem um sistema escolar que legitima uma cultura ${ }^{1}$ por meio do currículo, inserido no que Bourdieu (2014, p. 6) chama "campo administrativo ou campo de função pública", no seio do qual existe o sistema escola (MASSCHEILEIN; SIMONS, 2013), que origina a formação histórica da função professoral ou duma universalidade reconhecida, exigindo que "o professor seja mandatário da Instituição e que transmita o saber estabelecido, o saber canónico, que fale dos trabalhos já feitos em vez de trabalhar dos trabalhos pessoais, ou seja, incertos" (BOURDIEU, 2014, p. 67).

Sendo assim, o Estado veicula um conhecimento poderoso (YOUNG, 2016), marcado pela hegemonia de certos saberes que restituem o trivium disciplinar medieval, com valor acrescido para as tecnologias, como se fossem a panaceia da sociedade coeva, pelas ciências, que definem a objetividade de quem ensina e de quem aprende, e pelas línguas, qual veículo de comunicação entre as pessoas, se bem que o domínio esteja na consideração do inglês como língua franca.

Com efeito, o Estado é a garantia da existência de um projeto de educação e formação, com denominadores curriculares comuns, na esfera dos processos de globalização, como se o nacional se evaporasse e entranhasse no transnacional, uma máscara de muitos rostos e interesses, que está na base de um imperativo cosmopolita, defendido, entre outros, por Giddens (2014).

O Estado é, por conseguinte, sinónimo de uma educação obrigatória, consagrada como direito universal e constitucional, competindo-Ihe, de acordo com os Objetivos de Desenvolvimento Sustentável, da ONU, formulados em 2015, "assegurar a educação inclusiva, equitativa e de qualidade, e promover oportunidades de aprendizagem ao longo da vida para todos" (4ºbjetivo). Tal objetivo amplia o pressuposto da educação promovido pelo Estado-Nação em torno da teoria do capital humano, que se explorá neste texto mais à frente.

Que dizer, por isso, que a racionalidade de Estado agrafa ao ensino e à aprendizagem, figuras estereotipadas do mestre e do aprendiz, como se a sociedade fosse única e imutável no modo como organiza curricularmente a escola, na base da pedagogia prescritiva de Coménio (1657/1985) e de Ratke (1635/2008), da pedagogia racional de Kant (1803/2017), da pedagogia científica de Herbart (1806/2010), da teoria de instrução de Bruner (1966) e do racional de Tyler (1949).

Para os pós-estruturalistas, estas são algumas das metanarrativas que configuram a educação definida e subordinada ao Estado e engendram os caminhos labirínticos de uma engenharia burocrática (PACHECO, 2005), que se tem tornado numa abordagem preponderante tanto na organização de uma dada cultura escolar, como no desenvolvimento do seu processo de desenvolvimento do currículo, mesmo que os instrumentos pedagógicos utilizados sejam a metodologia de projetos e a metodologia de resolução e problemas, utilizados de forma sequencial e linear por meio da expressão "alinhamento curricular", supostamente inovadora, mas profundamente técnica.

\section{Sujeito}

Na finalidade pessoal da educação, revela-se a construção de uma matriz de comunidades de sujeitos, numa sociedade de aprendizagens, a partir de um conhecimento orientado para uma cidadania cosmopolita, ou seja, no reconhecimento de diferenças, identidades e subjetividades 
desconstruídas, nas ideias da pós-modernidade, pelo sujeito sem a existência de cânones ou padrões a seguir. Santos (2017) enfatiza na expressão cosmopolitismo subalterno a ideia de não silenciar vozes e identidades, conferindo ao sujeito a capacidade de reivindicar, aliás na continuidade de uma postura de vigilância crítica proposta por Horkheimer (1937/2000).

Se o Estado é lugar de conhecimento, o sujeito é o referencial para esse conhecimento, essencialmente se for marcante na sua construção a subjetividade, assim perspetivada por Pinar (2015a, p. 11):

Currículo, concebido como um verbo - currere - privilegia o conceito de indivíduo nos Estudos Curriculares. É um conceito, em si próprio, complexo. Cada um de nós é diferente, o que significa que cada um de nós tem uma imagem diferente, herdada geneticamente, assim como uma diferente educação, família e educadores, outros significativos e mais genericamente, em termos de raça, classe e género, por si próprios conceitos individualizados, infletidos por lugares, tempos e circunstâncias. Informado pela cultura e por outras forças homogeneizantes, cada um de nós é, ou pode ser, singular.

O sujeito é situado por Foucault (2011, p. 9) num contexto histórico, situado por entre as estruturas de poder, cuja hermenêutica é um princípio para o cuidado de si, que é "uma espécie de aguilhão que deve ser implantado na carne dos homens, cravado na sua existência, e constitui um princípio de agitação, um princípio de movimento, um princípio de permanente inquietude no curso da existência", pelo que "a necessidade do cuidado de si inscreve-se, pois, não somente no interior do projeto político, como no interior do deficit pedagógico" (Ibid., p. 35).

No texto que escreve sobre a hermenêutica do sujeito, o autor fala de "sujeito de ações, de comportamentos, de relações, de atitudes" (Ibid. p. 53), afirmando ao mesmo tempo que o professor ensina aptidões e capacidades, por meio da "mestria de competência, ou seja, a simples transmissão de conhecimentos, princípios, aptidões, habilidades, etc., aos mais jovens" (Ibid., p. 116). Assim, "o cuidado de si deve consistir no conhecimento de si" (Ibid., p. 63), situado em relações, "numa elaboração de si como objeto de saber e de conhecimentos possíveis", sendo professor ou o mestre "um operador na reforma do indivíduo e na formação do indivíduo como sujeito. É o mediador na relação do indivíduo com sua constituição de sujeito" (Ibid., p. 117). Com efeito, e aplicando-se ao processo de mudança que os sujeitos têm na sua ligação ao sistema educativo, tanto pela sua pertença a escolas como pela sua relação com o conhecimento, a universalidade afirma-se pelo particular, cujo absoluto subjetivo está interligado a uma lógica intersubjetiva no sentido habermasiano.

Em resposta à interrogação Qual é o conhecimento mais valioso?, a abordagem centrada no sujeito aponta para um conhecimento do quotidiano (YOUNG, 2016), ou de uma geografia de contextos, espaços e lugares, sem uma geografia dominada pelo nacional e transnacional, que cria e solidifica nas escolas denominadores curriculares comuns bastante contestados nas pedagogias não diretivas de Rogers e Illich (SNYDERS, 2001), entre outros, na pedagogia de conscientização de Freire $(1968 / 2006)^{2}$ e na conversação complexa e subjetiva de Pinar (2007; 2015b).

Reconhecer-se-á, porém, que as tecnologias - que dão e ampliam as vozes de sujeitos silenciados e uniformizados, com novas linguagens de expressão do corpo no espaço da subjetividade e da interação com os outros, como o ciborgue seja o potencial da inteligência artificial 
na maximização do uso das tecnologias digitais - estejam a contribuir para mudar formas de ensinar e aprender, com alterações radicais no domínio de competências cognitivas e na construção de redes de conhecimento, se bem que a googlização do conhecimento ${ }^{3}$ seja o reconhecimento do predomínio da sociedade da informação relativamente à sociedade de conhecimento. Todavia, as tecnologias digitais ${ }^{4}$ integram a suposta individualidade numa existência intrinsecamente coletiva, pois realçam a rede, as sabedorias das massas, a colaboração e a uniformização, numa construção de mentes de colmeia (hive minds), e não propriamente a identidade e a diversidade.

\section{Mercado}

O mercado institui-se como uma variante económica que regula a política, e não o contrário, na medida em que a doutrina neoliberal sustenta que o essencial do mercado está na concorrência. O princípio da concorrência é o que, para Foucault (2010, p. 157), constitui "a estrutura essencial de uma teoria do mercado". Assim, a concorrência é uma essência, uma ontologia, que estabelece "um jogo formal entre desigualdades. Não é um jogo natural entre indivíduos e comportamentos" (Ibid. p. 158), devendo-se "governar para o mercado e não governar por causa do mercado" (Ibid. p. 159). Tal omnipresença do mercado perfilhada pelos neoliberais "nada mais [é] do que a reativação de velhas teorias económicas já gastas" (Ibid. p. 173), como é o caso do pensamento de Adam Smith. Porém, o neoliberalismo ultrapassa esta e outras matrizes analíticas a partir do momento em que abandona o princípio clássico do laissez-faire e afirma o princípio da concorrência: "O neoliberalismo, portanto, não se vai colocar sob o signo do laissez-faire, mas, pelo contrário, sob o signo de uma vigilância de uma atividade, de uma intervenção permanente" (Ibid. p. 176).

Enquanto biopolítica, a governamentalidade é um processo de controle dos indivíduos cujos procedimentos garantem ao Estado a missão de intervir na educação como forma de valorização do capital humano, na medida em que o "homo oeconomicus é um empresário, é um empresário de si mesmo" (Ibid. p. 286). O sucesso depende de investimentos educativos, sendo "muito mais extensos, muito mais numerosos do que a simples aprendizagem escolar ou do que a simples aprendizagem profissional" (Ibid. p. 290).

Com fundamento, diz-se que o neoliberalismo reedita a teoria do capital humano como base das políticas económicas, sociais e educativas, e instaurada a denominada economia baseada no conhecimento, como se verifica, em nível da União Europeia, na Estratégia de Lisboa 2000 - "Para que as pessoas que entram no mercado do conhecimento participem ativamente na economia do conhecimento é necessário que o seu nível de formação seja suficientemente elevado" ${ }^{5}$, bem como na Estratégia Europa 2020 - crescimento inteligente, sustentável e inclusivo, sendo marcante a ideia de "desenvolver uma economia baseada no conhecimento e na inovação" 6 .

Mesmo que "de modo algum todo o indivíduo, todo o sujeito seja um homem económico" (FOUCAULT, 2010, p. 317), esta adjetivação torna-se uma matriz analítica para estudar a relação entre governo e indivíduo, sobretudo quando a liberdade deste é intersetada pelo con- 
trolo daquele, facto que se regista face ao critério de utilidade. Mas qual a aplicabilidade de tal natureza do homem à sociedade, em geral, e aos indivíduos, em particular?

Foucault responde a esta questão, indicando a utilização ótima de recursos em função da aceitação da realidade e da disciplinação a partir de técnicas comportamentais, que a escola psicológica de Skinner interpreta de forma concludente e que está na base de uma teoria da competência humana. Citando Gilbert, discípulo de Skinner, Freitas (2012, p. 382) afirma que "para se conseguir resultados com valor, é necessário reforçar, ou seja, premiar a performance, os resultados e não o comportamento em si", originando uma verdadeira engenharia de desempenho, buscando-se, segundo Gil (2014, p. 191), no caso dos professores, o "homem avaliado" e, no dos alunos, a "excelência do ensino", pensando-se "muitas vezes, mais com um espírito economicista do que na natureza do saber".

Esta lógica de mercado parte de uma noção de conhecimento utilitário e pragmático, de base competencial, sobretudo do saber-fazer, ligado à construção da experiência, conforme o pragmatismo que James (1907/2005) $)^{7}$ sublinha, e não tanto de um saber de background cognitivo, tal como aparece fundamentado na linguística chomskiana. A ênfase em competências operacionais e metodológicas, em detrimento de competências cognitivas, origina processos de desenvolvimento do currículo fundamentados em catálogos de saberes orientados pelo mundo do trabalho, como se o conhecimento fosse uma mercadoria, sujeito quer a regras de oferta e procura - e daí a formação com mais procura de emprego seja a que mais alunos tem e que engendra sistemas de seleção mais estratificados socialmente -, quer à responsabilização do indivíduo, sendo-lhe atribuído o mérito do sucesso ou a punição do insucesso.

Trata-se, com efeito, de um conhecimento traduzido em números, que aparecem em indicadores estatísticos nacionais e transnacionais que medem e avaliam a qualidade da educação e da formação, bastante propalados pela pedagogia de resolução de problemas e pela pedagogia de projetos orientados para resultados, centrada no aluno, escola essa com um processo de ensino e aprendizagem focado em tecnologias que privilegiam não tanto a transmissão de conhecimento ou a mera aquisição de conteúdos cognitivos, mas a expressão aprenderfazendo (learning by doing), um princípio da pedagogia ativa de Dewey (1900-1902/2002), inserida numa educação da realização, com professores que, através de uma estratégia de apoio e monitorização, "empoderam" os alunos. Outras vertentes desta racionalidade ligada ao neoliberalismo instauram a pedagogia sem sujeito (BUENO, 2003) e a pedagogia do fazer (MEIRIEU, 2009), em contraponto à pedagogia do dizer, de uma escola mais transmissiva, que é olhada com desconfiança pela sua improdutividade em termos de determinados resultados (FRIGOTTO, 2015).

Tal expressão de realização de tarefas tem sido revista concetualmente em atividades assíncronas de educação on-line, de que os MOOC (Massive Open Online Course) são uma evidência de quase ensinar tudo a todos, como preconizava Coménio em Didática Magna, bem como em atividades síncronas personalizadas, inovadoras e criativas, dominadas pelas dinâmicas de empreendorismo, acentuando o fosso entre "matérias antigas" e "matérias novas", como preconiza mediaticamente Prensky $(2014)^{8}$ por meio da proposta de um novo currículo mundial baseado num core curriculum cognitivo e num currículo estandardizado de habilidades 
digitais para pensar, criar, relacionar-se e atuar.

A escola de resultados, traduzidos em standards de conteúdos, capacidades e atitudes, tão presente nos testes nacionais e internacionais (caso do PISA), torna-se numa alquimia do conhecimento (POPKEWITZ, 2011), cuja validade orientada pelas necessidades do mercado equivale à procura de uma pedra filosofal, de modo a resolver os problemas da sociedade. Contudo, é uma escola que exclui e não inclui, partindo-se do princípio que a estratificação social é a base da competição e que a diversificação dos percursos escolares, segundo uma teoria curricular bifurcada entre as mãos e o cérebro (GOODSON, 2001), é um modo eficientista de promover não só a excelência escolar, em que os melhores são cada vez melhores e os fracos são cada vez mais fracos, mas também a competição entre professores, alunos e pais, unidos pelo receio em falhar (TAUBMAN, 2009).

A racionalidade de mercado traduz, assim, uma escola de uma aritmética curricular que é neotyleriana nos seus princípios de organização e implementação do processo de ensino e aprendizagem, sendo os profissionais de futuro formados a partir de formas individualizadas de aprender e ensinar, vivendo numa rede de comunicação ubíqua (SANTAELLA, 2013), capazes de atuar numa economia digital globalizada a partir de um repertório de competências adquirido num contexto de competição e no quadro de ciclos mais curtos, de acordo com o conceito de uma aprendizagem ao longo da vida, de que a geração alfa é um bom exemplo, ou seja, as crianças nascidas após 2010 e que têm uma relação intrínseca com as tecnologias digitais.

\section{ConcLuindo}

As mudanças que se observam nas práticas curriculares "são claramente influenciadas pelas mudanças colossais que estão ocorrendo atualmente na economia global" (GOODSON, 2008, p. 26), com o reposicionamento do papel do professor e o seu questionamento na construção de um presente em que a escola pública é criticada como um legado histórico e um bem social, com a afirmação de racionalidades que introduzem uma escola de resultados traduzidos em números e, por sua vez, em competências ligadas ao saber mais imediato e informacional, bastante longe de uma escola que deveria cultivar o pensamento emancipatório, tal como é defendido por Adorno (1971/2011), e afirmar a subjetividade, segundo Horkheimer (1947/2015, p. 11), quando critica a ênfase na racionalidade universal, da qual derivam "critérios para todas as coisas e seres" e o valor supremo dos números.

Se, em termos de conhecimento mais valioso, o currículo é o futuro que se está a construir no presente com aquilo que se aprende no passado, mais do que enunciar palavras de conclusão, é preferível convocar outras palavras que remetam para uma reflexão que cada um, ligado ou não ao sistema de educação e formação, pode fazer. Primeiro, são palavras do sociólogo UIrich Beck sobre a meta-mudança abrangente da sociedade no século XXI, depois palavras do maestro Lorenzo Viotti ${ }^{9}$ e, por último, palavras do linguista Nuccio Ordine:

Está em curso uma mudança cultural generalizada: uma nova compreensão da natureza e da sua relação com a sociedade, assim como uma outra compreensão de "nós" e dos "outros", da racionalidade social, da liberdade, da democracia e da legitimação - inclusivamente do indivíduo"; exigindo-se "uma nova ética de responsabilidade planetária orientada para o futuro. (BECK, 2016, p. 43). O lado humano conta 
muito nesta profissão. O maestro autoritário já passou de moda, mas na orquestra a democracia não serve. A responsabilidade do concerto é minha, como é minha a culpa se alguma coisa não funciona. (VIOTTI, 2017). As escolas e as universidades não podem sem geridas como empresas. (ORDINE, 2017, p. 90).

No entanto, e sem a pretensão de impor uma dada racionalidade escolar, já que nesse ambiente de aprendizagens combinam-se e reajustam-se diversas racionalidades, a educação e a formação são espaços de saberes que podem ser instrumentalizados de diversos modos e com finalidades muito diversas, incluindo a sua ideologização, já que toda a educação é intrinsecamente pessoal e política. Deste modo, aceitar-se-á que a escola é um lugar de controvérsias ${ }^{10}$, mas também de ideias que são partilhadas se, em primeiro lugar, for colocado o sujeito e não os resultados escolares transformados em números.

\section{REFERÊNCIAS}

ADORNO, T. Educação e emancipação. São Paulo: Paz e Terra, 1971/2011.

ARENDT, A. A condição humana. Lisboa: Relógio D’Água, 2006.

BECK, U. Sociedade de risco mundial. Em busca da segurança perdida. Lisboa: Edições 70, 2016.

BOURDIEU, P. Sobre o Estado: Edições 70, 2010.

BRUNER, J. Towards a theory of instruction. Cambridge: Harvard University Press.1966.

BUENO, S. Pedagogia sem sujeito, qualidade total e neoliberalismos na educação. São Paulo: FAPESP, 2003.

COMÉNIO, J. Didática Magna. Tratado da arte universal de ensinar tudo a todos. Lisboa: Fundação Calouste Gulbenkian, 1657/1985.

DEWEY, J. A escola e a sociedade. A criança e o currículo. Lisboa: Relógio D’Água, 1900-1902/2002.

FOUCAULT, M. Nascimento da biopolítica. Lisboa: Edições 70, 2010.

FOUCAULT, M. A hermenêutica do sujeito. São Paulo: Editora WMF Martins FONTES LTDA., 2011.

FREIRE, P. Pedagogia do oprimido. 44. ed. São Paulo: Paz e Terra, 1968/2006.

FREITAS, L.C. Os reformadores empresariais da educação: da desmoralização do magistério à destruição do sistema público de educação. Educação \& Sociedade, v. 33, n. 119, p. 379-404, 2012.

FRIGOTTO, G. A produtividade da escola improdutiva. Porto Alegre:Artmed, 2015.

GIDDENS, A. Este turbulento e poderoso continente. Que futuro para a Europa? Lisboa: Fundação Calouste Gulbenkian, 2014.

GIL, J. Pulsações. Lisboa: Relógio D’Água, 2014.

GOODSON, I. As políticas de currículo e de escolarização. Petrópolis: Editora Vozes, 2008.

GOODSON, I. O currículo em mudança. Estudos na construção social do currículo. Porto: Porto Editora, 2001. 
GRACIANI, M. S . Pedagogia social. São Paulo: Cortez Editora, 2014.

HERBART, J. F. Pedagogia geral. Lisboa: Fundação Calouste Gulbenkian,1806/2010.

HORKHEIMER, M. Teoría tradicional y teoría crítica. Barcelona: Paidós, 1937/2000.

HORKHEIMER, M. O eclipse da razão. Lisboa: Antígona, 1947/2015.

JAMES, W. Pragmatismo. São Paulo: Editora Martin Claret, 1907/2005.

KANT, I. Sobre a pedagogia. Lisboa: Edições 70, 2017.

LAPOUJADE, D. William James, a construção da experiência. São Paulo: n-1 Edições, 2017.

MASSCHEILEIN, J; SIMONS, M. Em defesa da escola: uma questão pública. Belo Horizonte: Autêntica, 2013.

MEIRIEU, P. Pedagogia entre o dizer e o fazer. Porto Alegre: Artmed, 2008.

NIETZSCHE, F. Escritos sobre educação. São Paulo: Edições Loyola, 1873/2003.

ORDINE, N. A utilidade do inútil. Manifesto. Lisboa: Kalandraka Editora Portugal, 2017.

PACHECO, J. A. Estudos Curriculares. Para a compreensão crítica da educação. Porto: Porto Editora, 2005.

PINAR, W. F. Educational experience as lived: knowledge, history, alterity. New York: Routledge, $2015 \mathrm{a}$.

PINAR, W. F. Foreword. In: HENDERSON, J. G. et al. Reconceptualizing curriculum development. Inspiring and informing action. New York: Routledge, 2015b, p. XI-XVI.

PINAR, W. F. O que é a teoria curricular? Porto: Porto Editora, 2007.

POPKEWITZ, T. (2011). PISA: Numbers, standardizing conduct, and the alchemy of Scholl subjects. In: M. A. PEREYRA, M. A., KOTTHOFF. H., COWEN, R. (Eds.), PISA under examination. Changing knowledge, changing tests, and changing schools. Rotterdam: Sense Publishers, 2011, p. 31-46.

PRENSKY, M. The world needs a new curriculum, Educational Technology, v.5, n.4, p. 3-15, 2014.

PRENSKY, M. The World needs a new curriculum. Acesso em: outubro de 2017: http://marcprensky.com/ wp-content/uploads/2013/05/Prensky-5-The World_Needs_a_New_Curriculum.pdf

RATKE, W. Escritos sobre a nova arte de ensinar. Textos escolhidos. Campinas: Autores Associados, $1635 / 2008$.

RECHIA, K.C., MENDES, G.L., PREVE, A.M. Apresentação. IN: LARROSA, J. (Org.), Elogio da escola. Belo Horizonte: Autêntica, 2017, pp. 9-15.

SANTAELLA, L. Comunicação ubíqua: Repercussões na cultura e na educação, São Paulo: Editora Paulus, 2013.

SANTOS, B. S. As bifurcações da ordem. Revolução, cidade, campo e indignação. Coimbra: Almedina, 2017.

SNYDER, T. Terra negra. O holocausto como história e aviso. Lisboa: Bertrand Editora, 2016.

SNYDERS, G. Para onde vão as pedagogias não-diretivas? São Paulo: Centauro Editora, 2001. 
TAUBMAN, P. (2009). Teaching by numbers. New York: Routledge, 2009.

TYLER, R. Basic principles of curriculum and instruction. Chicago: The Chicago University Press, 1949.

WILLIAMSON, B. The future of the curriculum. School knowledge in the digital age. Stirling: The MIT Press, 2013.

YOUNG, M. F. Por que o conhecimento é importante para as escolas do século XXI? Cadernos de Pesquisa, v. 46, n. 159, p. 18-37, 2016.

Artigo recebido em: 12/12/2017

Aprovado em: 22/01/2018

Contato para correspondência:

José Augusto Brito Pacheco. E-mail: jpacheco@ie.uminho.pt

NOTAS

1 Para uma análise crítica do Estado-cultura, Vide: Friedrich Nietzsche (1873/2003, p. 101), falando de uma "cultura de Estado uniformizada" e de um Estado como "mistagogo da cultura", pois, com a sua voz profunda, o Estado diz "Sim! Tu és a educação! Tu és a cultura!"

2 Maria Stelio Graciani (2014) aborda esta noção de forma ampla, com contributos para a compreensão da pedagogia de Paulo Freire.

3 A ideia primeira dos fundadores do Google era a de reunir todo conhecimento num só espaço de múltiplas.

4 Ideias exploradas por Franklin Foer, THE WASHINGTON POST/PÚBLICO, 5 de novembro de 2017, no ensaio "Como Silicon Valley está a apagar a nossa individualidade".

5 Cf. Conselho Europeu extraordinário de Lisboa (março de 2000). Para uma Europa da inovação e do conhecimento.

6 Cf. A estratégia Europa 2020 (junho de 2011). Bruxelas.

$7 \quad$ Ver, também, David Lapoujade (2017).

8 Cf., de igual modo, Ben Williamson (2013).

9 Cf. Lorenzo Viotti, Entrevista ao jornal PÚBLICO, 14 de outubro de 2017 (maestro britânico da orquestra Gulbenkian, Lisboa).

10 Tais controvérsias, incluindo as alterações introduzidas pelas tecnologias digitais, podem ser identificadas em Elogio da escola, 2017, p. 15. cuja apresentação é feita por Karen Christine Rechia, Geovana Lunardi Mendes e Ana Maria Preve, na afirmação de que a "ideia de elogio é diferente da de defesa, celebração ou apologia da escola. Tomamos elogio no sentido grego de mostrar o que é, ou seja, de mostrar as virtudes da escola". 